\title{
WCCo/cBN composites produced by pulse plasma sintering method
}

\author{
Marcin Rosinski • Andrzej Michalski
}

Received: 22 October 2011/Accepted: 24 April 2012/Published online: 23 May 2012

(C) The Author(s) 2012. This article is published with open access at Springerlink.com

\begin{abstract}
WCCo/cBN composites have been considered as a next-generation material for use in cutting-tool edges, being characterized by an optimal combination of hardness and toughness. They can be used instead of WCCo/ diamond composites in machining of iron-based materials. The major challenge in sintering these composites is to produce a well-bonded interface between the WCCo matrix and cBN particles. In this study, WCCo/cBN composites were fabricated by the pulse plasma sintering technique. The aim of this work is to obtain sintered parts with density near the theoretical value and with very good contact between the $\mathrm{cBN}$ particles and WCCo matrix. $\mathrm{cBN} /$ cemented carbide containing $30 \mathrm{vol} \%$ of $\mathrm{cBN}$ particles was produced using a mixture of 6 and $12 \mathrm{wt} . \%$ Co-added WC powder, with WC grain size of $0.4 \mu \mathrm{m}$ and $\mathrm{cBN}$ powder with grain size ranging from 4 to $40 \mu \mathrm{m}$. Scanning electron microscopy (SEM) observations of the microstructure and diffraction phase examinations did not show the presence of $\mathrm{hBN}$ phase. The specific heating conditions used to consolidate the material using high-current pulses hamper the transformation of cBN into $\mathrm{hBN}$ and ensure a strong bond between the $\mathrm{cBN}$ particles and the cemented carbide matrix. Fractures through the $\mathrm{WCCo} / \mathrm{cBN}$ composite showed that only few $\mathrm{cBN}$ particles were torn out from the cemented carbide matrix, with most of them having been cleaved along the fracture plane. This provides evidence that the bond at the $\mathrm{WCCo} / \mathrm{cBN}$ interface is mechanically strong. Composites sintered at temperature of $1,200{ }^{\circ} \mathrm{C}$ under pressure of $100 \mathrm{MPa}$ for $5 \mathrm{~min}$ had density near the theoretical value. Increase of the sintering
\end{abstract}

M. Rosinski $(\bowtie) \cdot$ A. Michalski

Faculty of Materials Science and Engineering, Warsaw

University of Technology, Warsaw, Poland

e-mail: ninmar@inmat.pw.edu.pl temperature to $1,200{ }^{\circ} \mathrm{C}$ resulted in an increase of the hardness to $2,330 \mathrm{HK} 1$ for the $\mathrm{WC} 6 \mathrm{Co} / \mathrm{cBN}(1 / 3) \mathrm{com}$ posite and to $2,160 \mathrm{HK} 1$ for the $\mathrm{WC} 6 \mathrm{Co} / \mathrm{cBN}(37 / 44)$ composite.

\section{Introduction}

Cubic boron nitride is a material next to diamond in hardness [1], but its thermal stability and chemical neutrality are superior to those of diamond. Because of these advantages, cubic boron nitride is widely used for manufacture of cutting tools. Without the use of a catalyst, cubic boron nitride is obtained at temperature between 2,300 and $3,300{ }^{\circ} \mathrm{C}$ and pressure of 6-10 $\mathrm{GPa}$ as a result of the phase transformation of $\mathrm{hBN}$ with hexagonal structure into a cBN regular structure [2] or, with the participation of a catalyst, at a temperature between 1,000 and $1,700{ }^{\circ} \mathrm{C}$ under pressure of 2-6 GPa [3]. cBN produced without participation of a catalyst can be sintered in the form of polycrystalline plates suitable for use as cutting tools. When produced with the participation of a catalyst, $\mathrm{cBN}$ has the form of a powder with grain size ranging from $10 \mathrm{~nm}$ to $2 \mu \mathrm{m}$. Composites sintered from this powder using high-melting materials (most often titanium and its compounds) as a binding phase are also used in cutting tools [4]. However, to avoid the transformation of cBN into low-hardness $\mathrm{hBN}$, they must be sintered under pressure of 5-6 GPa, which substantially increases their production cost.

Another material widely used for cutting tools is tungsten carbide, which is the next hardest material after $\mathrm{cBN}$. Tungsten carbide is commonly sintered with cobalt as the binding phase. Thanks to its high hardness, good resistance to frictional wear, and high resistance to cracking, over $50 \%$ of cutting tools are made of cemented carbide. 
Its hardness can be significantly increased by replacing part of the carbide phase with cubic boron nitride, which is several times harder. In addition, the $\mathrm{cBN}$ particles can considerably increase the fracture toughness of the material due to the crack deflection effect, wherein crack energy is absorbed [5].

cBN/WCCo composites cannot however be produced by conventional sintering, which is conducted at temperature between 1,300 and $1,500{ }^{\circ} \mathrm{C}$ in the presence of the liquid phase [6], since within this temperature range, cBN undergoes transformation into $\mathrm{hBN}$, and the presence of the cobalt-rich liquid phase enhances this transformation rate.

Composites with cBN particles dispersed in cemented carbides, known as cubic boron dispersed carbides (CBDC), were obtained by Martinez and Eceberria [5] by sintering using the method of hot isostatic pressing (HIP) at temperature between 1,100 and $1,200{ }^{\circ} \mathrm{C}$ under pressures of up to $200 \mathrm{MPa}$. The CBDC composites thus obtained were dense, and no phase transformation of $\mathrm{cBN}$ into $\mathrm{hBN}$ took place during the sintering process. Yaman et al. [7] obtained a CBDC composite using WC-6 wt.\% Co powder and a $\mathrm{cBN}$ powder with grain size of 0.8 and $5 \mu \mathrm{m}$, sintering the powders by the spark plasma sintering (SPS) method at temperature of $1,300{ }^{\circ} \mathrm{C}$ and pressure of $75 \mathrm{MPa}$. Shi et al. [8] sintered CBDC composites using a nanocrystalline (WC-10 wt.\% Co) powder and a $\mathrm{CBN}$ powder with titanium-covered grains with size of $150-375 \mu \mathrm{m}$. The sintering process was conducted by the SPS method at temperature of $1,240{ }^{\circ} \mathrm{C}$.

In the present experiments, boron nitride dispersed cemented carbides (BNDCC) composites were sintered by the pulse plasma sintering (PPS) method, which uses periodic high-current electric pulses generated by discharging a capacitor battery. The energy of several $\mathrm{kJ}$ stored in the capacitors is delivered during several hundred microseconds, creating specific sintering conditions. The PPS method has been used for sintering a wide variety of materials, such as nanocrystalline cemented carbides [9],
WC/Ti-cBN [10], WCCo/diamond [11], and $\mathrm{Cu} /$ diamond [12] composites.

The aim of the present study is to determine the optimum parameters for sintering the composites with $\mathrm{cBN}$ particles dispersed in a cemented carbide matrix using the PPS method. The effect of sintering temperature on the phase composition of the composites with various grades of cBN powder added and with various cobalt contents in the cemented carbide matrix was examined.

\section{Experimental procedures}

BNDCC composites were produced using a mixture of WC powder, Co powder, and $\mathrm{cBN}$ powder of various grades. Table 1 lists the powder grades used for the fabrication of the BNDCC composites.

The WC powder with 6 and 12 wt.\% cobalt added was mixed using cemented carbide balls (ball-to-powder mass ratio of $1: 1$ ) in a Turbula mixer at rotational speed of $70 \mathrm{rpm}$ for $10 \mathrm{~h}$. Then, the mixture was mixed with 30 vol.\% of $\mathrm{cBN}$ powder particles using the same mixing parameters. Figure 1 shows SEM images of the $c B N$ powders used in the experiments. The compositions of the mixtures of the powders are given in Table 2.

The powder mixtures were sintered to obtain samples $20 \mathrm{~mm}$ in diameter and $1.8 \mathrm{~mm}$ high. The composites were sintered at temperatures of $1,100,1,150$, and $1,200{ }^{\circ} \mathrm{C}$, whereas cemented carbides with 6 and 12 wt.\% cobalt

Table 1 Powders used for producing the BNDCC composites

\begin{tabular}{ll}
\hline Powder & $d(\mu \mathrm{m})$ \\
\hline $\mathrm{WC}$ & 0.4 \\
Co & 1 \\
$\mathrm{cBN}(1 / 3)$ & $1-3$ \\
$\mathrm{cBN}(37 / 44)$ & $37-44$ \\
\hline
\end{tabular}
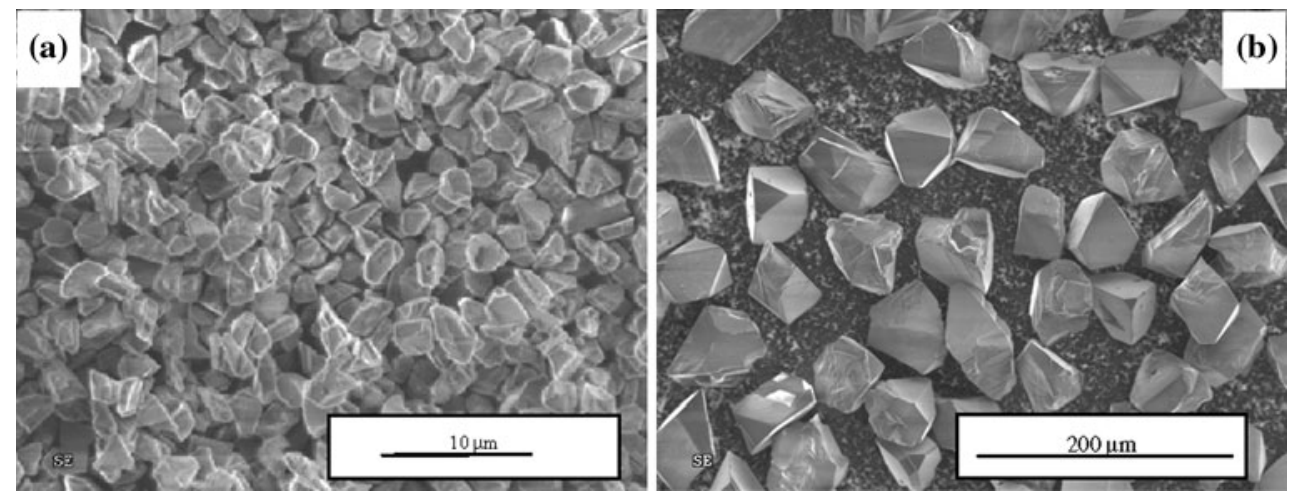

Fig. 1 SEM images of cBN powders used for producing BNDCC composites: a 1/3 $\mu \mathrm{m}, \mathbf{b} 37 / 44 \mu \mathrm{m}$ 
Table 2 Composition and designations of the powder blends

\begin{tabular}{lll}
\hline Label & Composition & TD $\left(\mathrm{g} / \mathrm{cm}^{3}\right)$ \\
\hline WC6Co & $(\mathrm{WC}+6 \mathrm{wt} . \% \mathrm{Co})$ & 14.85 \\
WC12Co & $(\mathrm{WC}+12 \mathrm{wt} . \% \mathrm{Co})$ & 14.33 \\
$\mathrm{WC6Co} / \mathrm{cBN}(1 / 3)$ & $30 \mathrm{vol} \% \mathrm{cBN}(1 / 3)+(\mathrm{WC}+6 \mathrm{wt} \% \mathrm{Co})$ & 11.44 \\
$\mathrm{WC6Co} / \mathrm{cBN}(37 / 44)$ & $30 \mathrm{vol} \% \mathrm{cBN}(37 / 44)+(\mathrm{WC}+6 \mathrm{wt} \% \mathrm{Co})$ & 11.44 \\
$\mathrm{WC12Co} / \mathrm{cBN}(37 / 44)$ & 30 vol.\% cBN $(37 / 44)+(\mathrm{WC}+12 \mathrm{wt} . \% \mathrm{Co})$ & 11.08 \\
\hline
\end{tabular}

added were sintered at temperature of $1,100{ }^{\circ} \mathrm{C}$. The sintering process was conducted in a PPS apparatus in vacuum of $5 \times 10^{-3} \mathrm{~Pa}$ using a graphite die. Figure 2 shows a schematic diagram of a cycle of the sintering process.

In the first stage of the process, the powder mixture was heated to temperature of $600{ }^{\circ} \mathrm{C}$ (at heating rate of $700{ }^{\circ} \mathrm{C} /$ $\mathrm{min}$ ) and maintained at this temperature under load of $60 \mathrm{MPa}$ for $3 \mathrm{~min}$ to remove absorbed gasses from the powder mixture. The pressure was increased to $100 \mathrm{MPa}$, and the sample was heated to the sintering temperature (at heating rate of $340{ }^{\circ} \mathrm{C} / \mathrm{min}$ ), which was maintained for $5 \mathrm{~min}$. In the final stage, the samples were cooled to room temperature in vacuum of $5 \times 10^{-3} \mathrm{~Pa}$ under load of $100 \mathrm{MPa}$. Table 3 gives the sintering process parameters used for the BNDCC composites and cemented carbides.

The phase composition of the sintered materials was determined with a Philips PW 1140 X-ray diffractometer

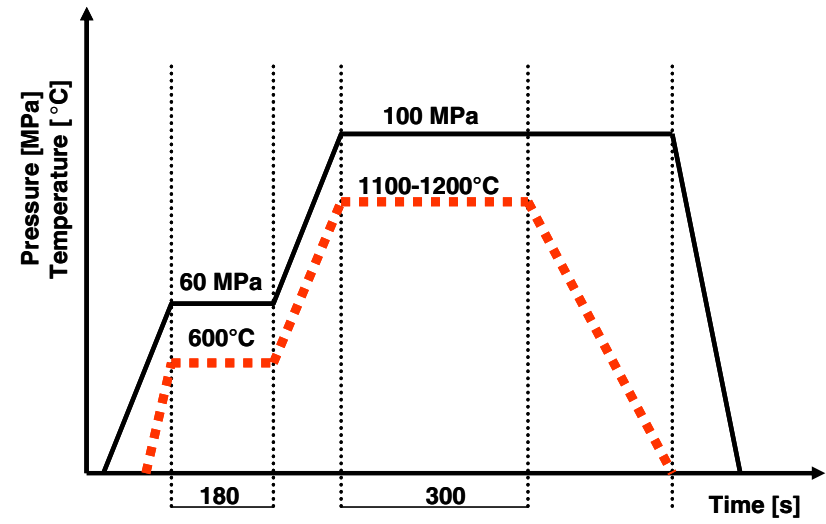

Fig. 2 Schematic representation of the PPS process

Table 3 Sintering process parameters

\begin{tabular}{lll}
\hline Parameter & Stage I & Stage II \\
\hline Temperature $\left({ }^{\circ} \mathrm{C}\right)$ & 600 & $1,100,1,150,1,200$ \\
Time $($ min) & 3 & 5 \\
Pulse energy $(\mathrm{kJ})$ & 5.4 & 4.5 \\
Voltage $(\mathrm{kV})$ & 6 & 5.5 \\
Pulse frequency $(\mathrm{Hz})$ & 0.3 & 2 \\
Load $(\mathrm{MPa})$ & 60 & 100 \\
Pressure $(\mathrm{Pa})$ & $5 \times 10^{-3}$ & $5 \times 10^{-3}$ \\
\hline
\end{tabular}

equipped with a PW1050 goniometer using Co $\mathrm{K}_{\alpha}$ radiation. The microstructure and chemical composition were examined in a Hitachi S3500N scanning electron microscope equipped with a Noran Vantage EDS-Thermo system designed for chemical analyses. Hardness was determined using a ZWICK hardness meter under load of $1 \mathrm{~kg}$ (the size of the indent was $84 \mu \mathrm{m}$ at 2,100 HK1). The density of the composites was measured by immersing the samples in water and using Archimedes' principle; the measured density values were compared with the theoretical density calculated from the rule of mixtures (Table 2).

\section{Results and discussion}

Figure 3 shows the density of the composites as a function of their sintering temperature for various grades of cBN powder added to the cemented carbide matrix enriched with 6 or 12 wt. $\%$ of cobalt.

The density of the $\mathrm{WC} 6 \mathrm{Co} / \mathrm{cBN}(1 / 3)$ and $\mathrm{WC} 6 \mathrm{Co} /$ cBN(37/44) composites (for designations, see Table 1) was below the theoretical density (TD), being $92.6 \%$ of TD for the $\mathrm{WC} 6 \mathrm{Co} / \mathrm{cBN}(1 / 3)$ composite and $98.6 \%$ of TD for the WC6Co/cBN(37/44) composite, whereas without cBN addition, the density of cemented carbide $+6 \mathrm{wt} . \%$ Co sintered at $1,100{ }^{\circ} \mathrm{C}$ by PPS was $14.85 \mathrm{~g} / \mathrm{cm}^{3}(99.5 \% \mathrm{TD})$

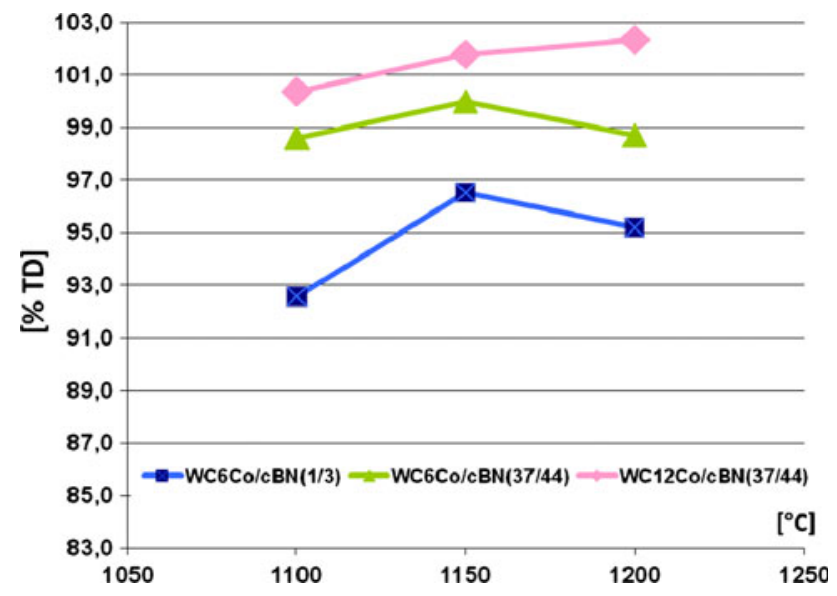

Fig. 3 Relative density versus temperature of composites sintered with various grades of $\mathrm{cBN}$ powder and cemented carbide matrix with 6 and 12 wt.\% Co added 

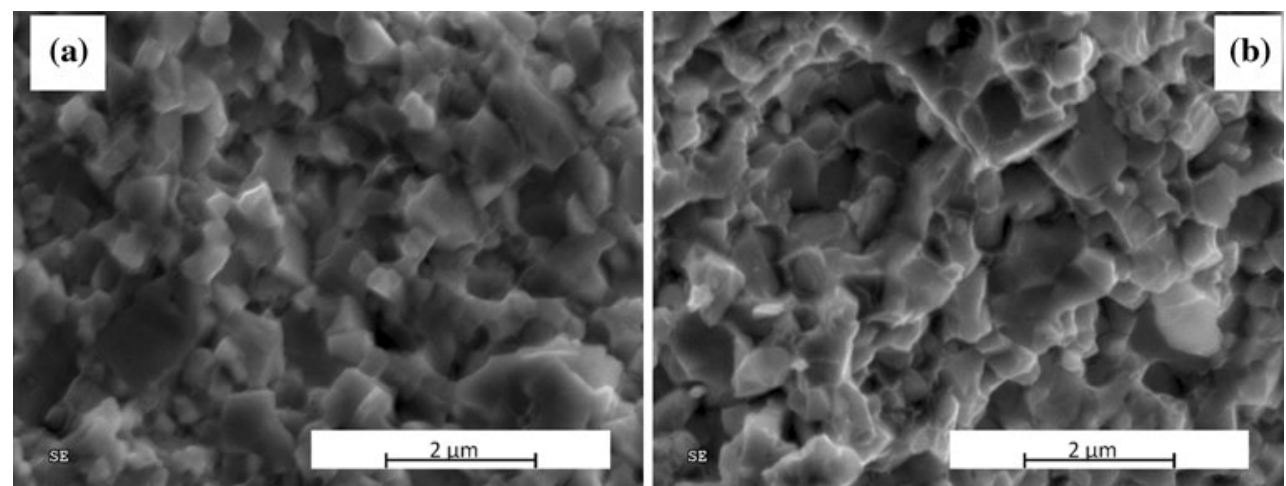

Fig. 4 SEM micrograph of the fracture surface of cemented carbides sintered at $T=1,100{ }^{\circ} \mathrm{C}$ for $t=5 \mathrm{~min}$ : a 6 wt. $\%$ Co, b 12 wt. $\%$ Co

and that of cemented carbide containing $12 \mathrm{wt} . \%$ Co was $14.33 \mathrm{~g} / \mathrm{cm}^{3}$. This indicates that addition of $\mathrm{cBN}$ particles decreases the sinterability compared with the cemented carbide itself. Figure 4 shows SEM images of the fracture surface of cemented carbide with 6 and 12 wt.\% Co added.

When the sintering process was conducted at temperature of $1,150{ }^{\circ} \mathrm{C}$, the density of the WC6Co/cBN $(37 / 44)$ composite increased to $100 \%$ of $\mathrm{TD}$ and that of the WC6Co/cBN(37/44) composite increased to $96.5 \%$ of TD. However, further increase of the sintering temperature to $1,200{ }^{\circ} \mathrm{C}$ decreased the density to $98.7 \%$ of TD for the WC6Co/cBN $(37 / 44)$ composite and $95.2 \%$ of TD for the WC6Co/cBN $(1 / 3)$ composite. It might be supposed that this density decrease could be connected with partial transformation of $\mathrm{cBN}$ to $\mathrm{hBN}$ during sintering at $1,200{ }^{\circ} \mathrm{C}$, but diffraction examinations of these composites did not show the presence of the hBN phase (Fig. 5). It should, however, be realized that the diffraction peaks from the $\mathrm{hBN}$ phase may be very weak because of the very high absorption coefficient of the WC phase.

According to Ref. [6], the presence of a cobalt-rich liquid phase enhances the transformation rate of $\mathrm{cBN}$ into hBN phase. The presence of the liquid cobalt phase during pulse plasma sintering is due to the specific heating method used while sintering the material. In the PPS method, the powder is heated by periodically repeated electric current pulses with amplitude of about $50 \mathrm{kA}$ and pulse duration of about $0.5 \mathrm{~ms}$. Just as in the field assisted sintering technique (FAST) and SPS methods, the surfaces of the material grains are heated temporarily to very high temperature, of the order of several thousand degrees Celsius [13]. After the current flow stops, the temperature decreases very quickly to the assumed sintering temperature. The appearance of the liquid cobalt phase in the PPS process was also confirmed by the present experiments, since the WC grains visible in the microstructure of the cemented carbides that were PPSsintered at temperature of $1,100{ }^{\circ} \mathrm{C}$ (Fig. 4) were evenly surrounded by the binding cobalt phase, providing evidence that the high-current pulse sintering proceeded with participation of a liquid cobalt phase. When the sintering process occurs without participation of the liquid phase, cobalt usually occurs in the form of agglomerates and is distributed nonuniformly in the cemented carbide matrix [5], even though the sintering process is conducted at temperature of $1,100{ }^{\circ} \mathrm{C}$, which is below the melting point of cobalt.

The density decrease as a result of increasing the sintering temperature from 1,150 to $1,200{ }^{\circ} \mathrm{C}$ cannot be connected with partial transformation of $\mathrm{cBN}$ into $\mathrm{hBN}$ phase because, in contrast to Ref. [6], the present study did not confirm that the cobalt phase, at the temperatures employed
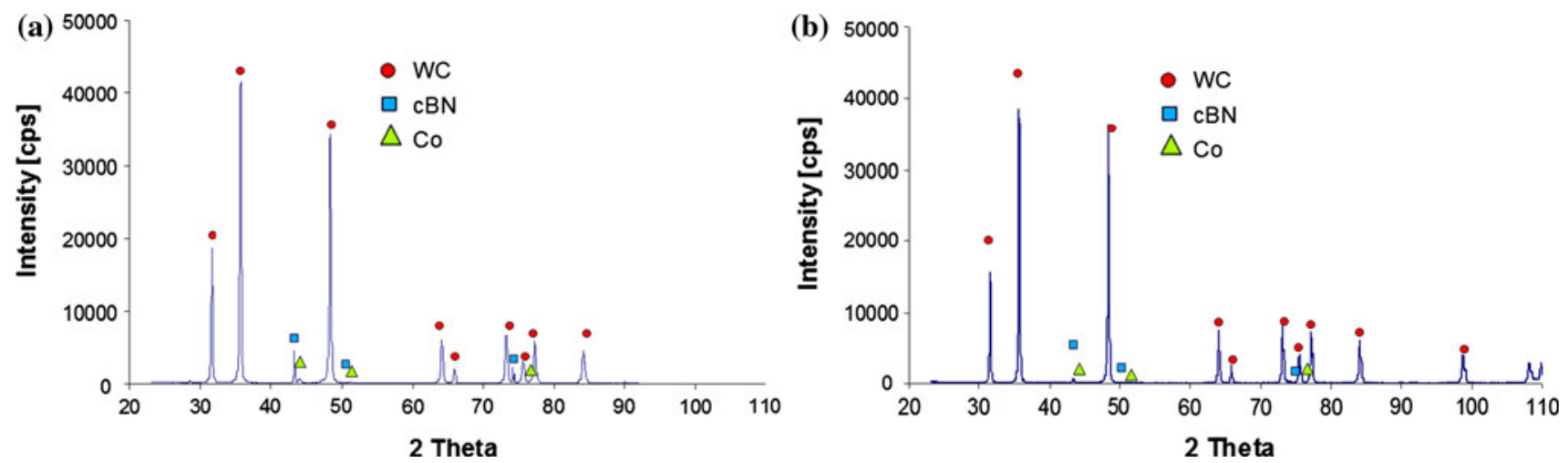

Fig. 5 XRD diagrams: a WC6Co/cBN(1/3) composite, b WC6Co/cBN(37/44) composite, sintered at $1,200{ }^{\circ} \mathrm{C}$ 
Fig. 6 X-ray diffraction diagrams of the $\mathrm{Co} 70 \mathrm{cBN}$ sintered at $1,200{ }^{\circ} \mathrm{C}$

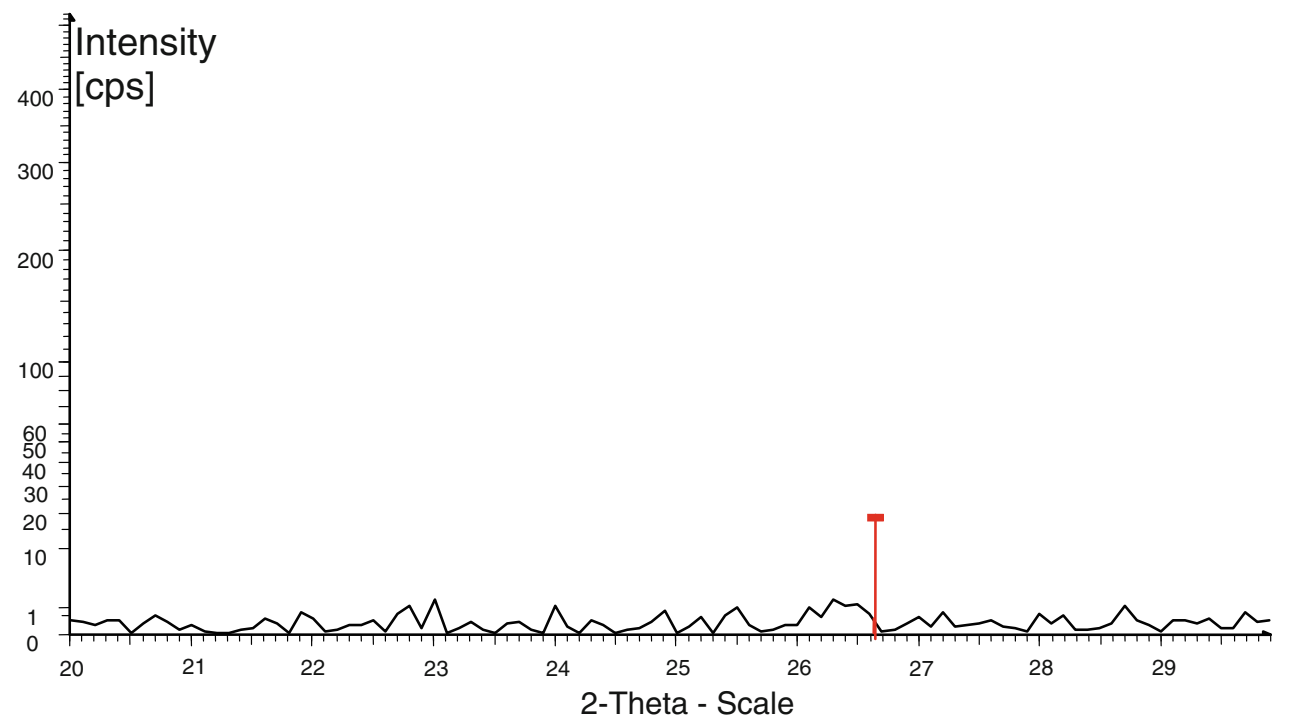

$\square$ 01-085-1068 (C) - Boron Nitride - BN - Y: $20.09 \%$ - d x by: 1. - WL: 1.54056 - Hexagonal - a 2.51000 - b 2.51000 - c 6.69000 here, enhances the transformation rate of $\mathrm{cBN}$ into $\mathrm{hBN}$ phase. XRD examinations of an additionally prepared mixture of $\mathrm{Co}$ and $\mathrm{cBN}$ powders $[70 \mathrm{vol} . \% \mathrm{Co} / 30 \mathrm{vol} . \%$ $\operatorname{cBN}(1 / 3)]$ sintered at temperature of $1,200{ }^{\circ} \mathrm{C}$ for $5 \mathrm{~min}$ did not show the presence of hexagonal boron nitride (red vertical line-hBN phase) (Fig. 6).

Observations of the fracture surface of composites sintered at temperature of $1,200{ }^{\circ} \mathrm{C}$ also did not reveal the presence of hBN phase (which could be visible as flakes) on the surface of cBN particles. Figure 7 shows SEM images of the fracture surface of the $\mathrm{WC} 6 \mathrm{Co} / \mathrm{cBN}(1 / 3)$ and WC6Co/cBN(37/44) composites.

As can be seen from Fig. 7, the cBN particles are uniformly distributed in the cemented carbide matrix. No pores or hBN precipitates are visible around the $\mathrm{cBN}$ particles, which are firmly bound with the cemented carbide matrix. Only a few
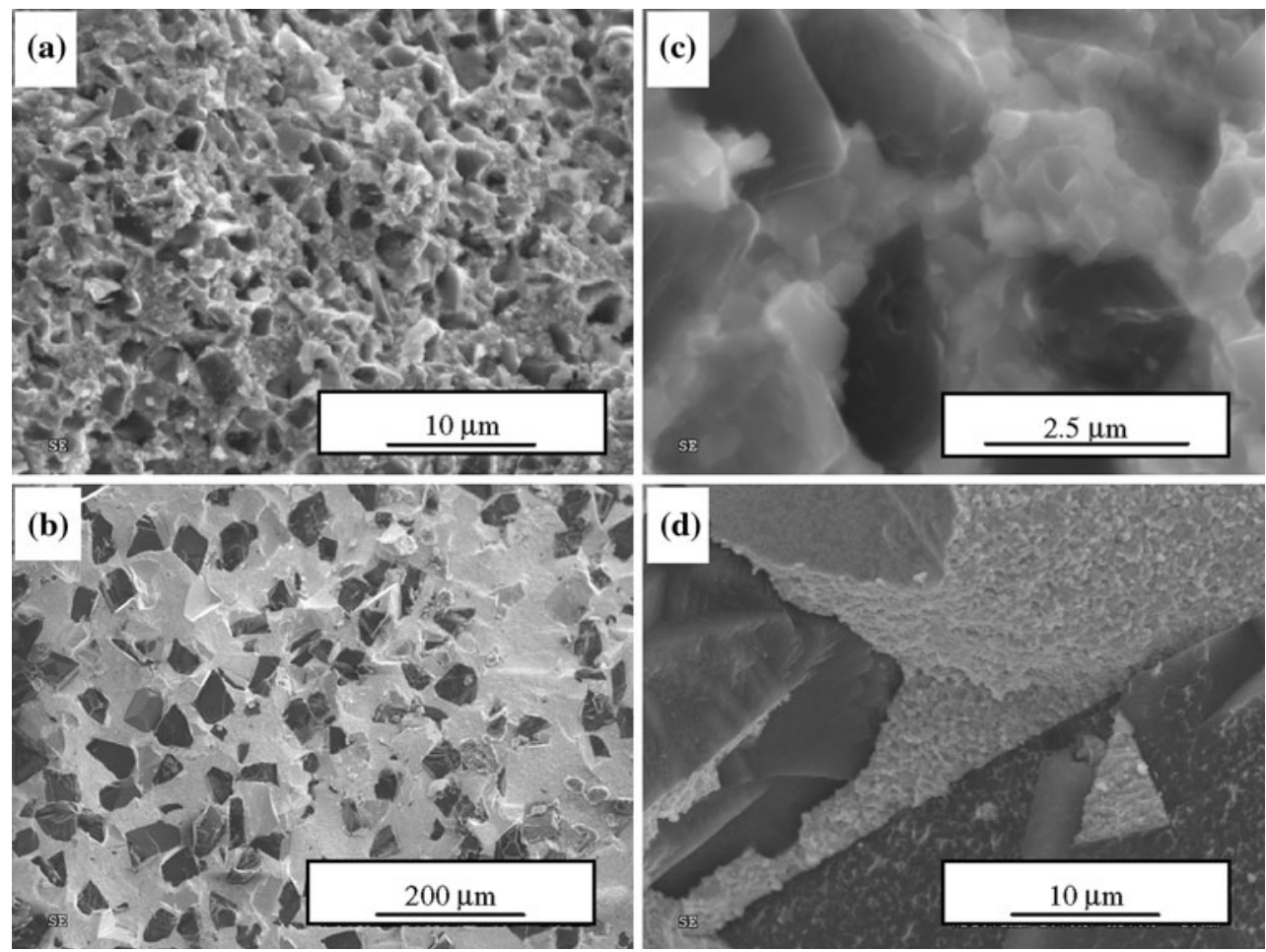

Fig. 7 SEM images of the fracture surface of: a WC6Co/cBN $(1 / 3)$ composite, and b WC6Co/cBN $(37 / 44)$ composite sintered at $1,200{ }^{\circ} \mathrm{C}$; $\mathbf{c}, \mathbf{d}$ show higher magnifications of $\mathbf{a}$ and $\mathbf{b}$, respectively 
cBN particles torn out from the matrix can be seen on the fracture surface, while, during the fracture, most of them broke across the crystal but remained embedded in the matrix.

The density of the composite with the matrix with 12 wt.\% Co added (Fig. 3) increases with increasing sintering temperature. When sintered at $1,100{ }^{\circ} \mathrm{C}$, the $\mathrm{WC} 12 \mathrm{Co} / \mathrm{cBN}(37 / 44)$ composite has density of $11.12 \mathrm{~g} /$ $\mathrm{cm}^{3}$, i.e., exceeding the theoretical value by about $0.4 \%$, but when this composite was sintered at $1,200{ }^{\circ} \mathrm{C}$, its density increased to $11.34 \mathrm{~g} / \mathrm{cm}^{3}$, which is higher than the theoretical value by about $2.3 \%$. It might be supposed that this increase of density during sintering at $1,200{ }^{\circ} \mathrm{C}$ is due to the formation of a new phase with higher density. However, examination of the phase composition of this composite did not reveal any new phases (Fig. 8), the only phases identified in the composite being $\mathrm{cBN}, \mathrm{WC}$, and Co. The same assumption can be make as in the case of the $\mathrm{WC} 6 \mathrm{Co} / \mathrm{cBN}(1 / 3)$ and $\mathrm{WC} 6 \mathrm{Co} / \mathrm{cBN}(37 / 44)$ composites, i.e., that the diffraction peaks from the $\mathrm{hBN}$ phase may be very weak because of the very high absorption coefficient of the WC phase.
Figure 9 shows SEM images of the fracture surface of the $\mathrm{WC} 12 \mathrm{Co} / \mathrm{cBN}(37 / 44)$ composite. It can be seen that, just as for the composite with $6 \mathrm{wt} \%$ of $\mathrm{Co}$, the $\mathrm{cBN}$ particles are uniformly distributed in the cemented carbide matrix and are well bound with it, with only a few particles being torn out of the matrix. Most of the particles broke across the crystal but remained embedded in the matrix. When observing the $\mathrm{cBN}$ particles at greater magnification, we can see regions on their surfaces corresponding to the binding cobalt phase, which is a constituent of the matrix (Fig. 8b).

The EDS analysis (Fig. 10) and the point EDX analysis (Fig. 11) of these regions revealed the presence of cobalt and tungsten.

Based on the microstructural observations, and analysis of the phase composition and element distribution in the $\mathrm{cBN} / \mathrm{WCC}$ composite with the cemented carbide matrix enriched with $12 \mathrm{wt} \%$ of $\mathrm{Co}$, we can suppose that the density higher than the theoretical value is due to the formation of an intermetallic phase $\left(\mathrm{WCoB}, \mathrm{W}_{2} \mathrm{CoB}_{2}\right)$ which strongly binds $\mathrm{cBN}$ with the cemented carbide.
Fig. 8 X-ray diffraction diagrams of the $\mathrm{WC} 12 \mathrm{Co} /$ cBN(37/44) composite sintered at $1,200{ }^{\circ} \mathrm{C}$
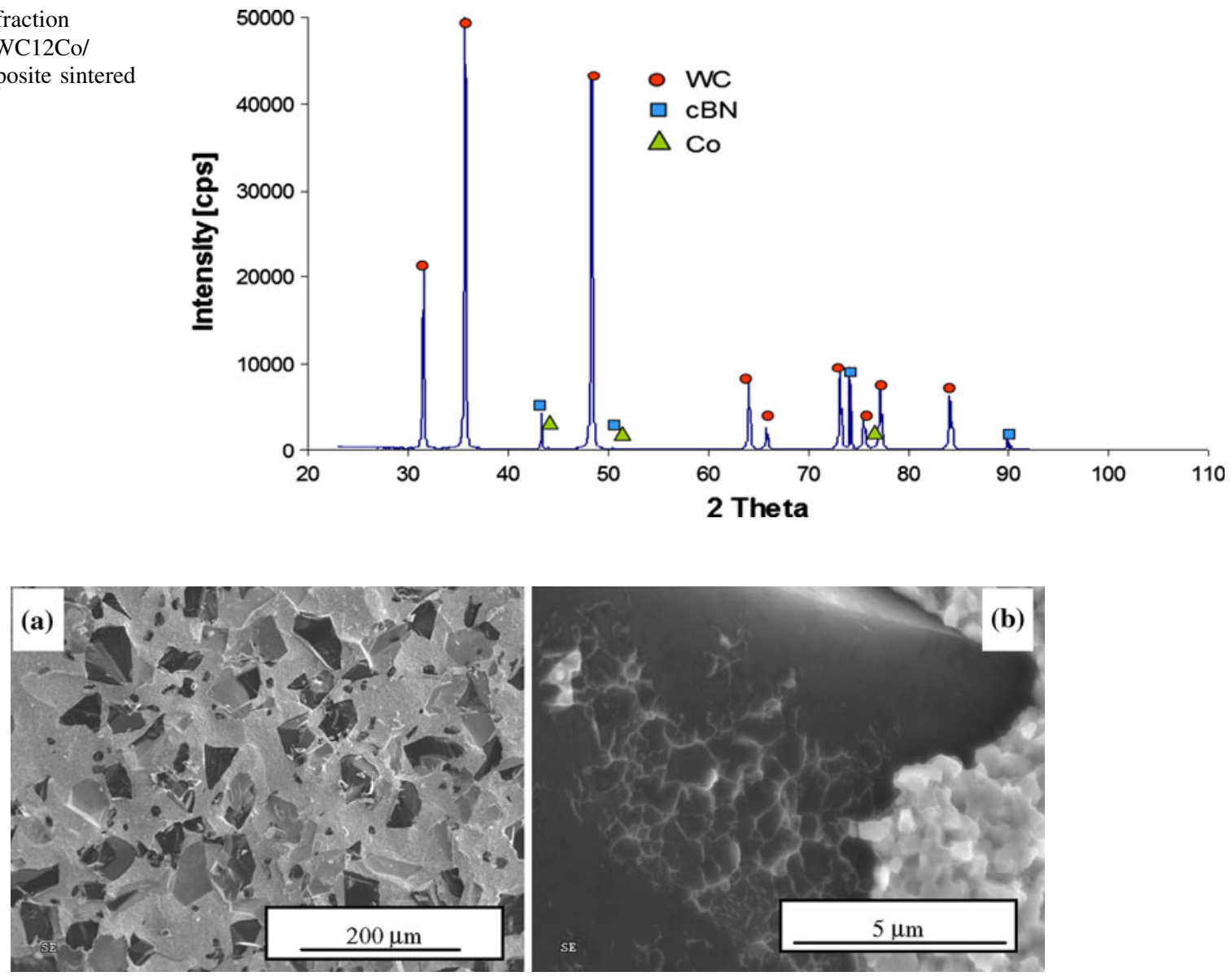

Fig. 9 SEM images of a fracture of the WC12Co/cBN(37/44) composite sintered at $1,100{ }^{\circ} \mathrm{C}$ 

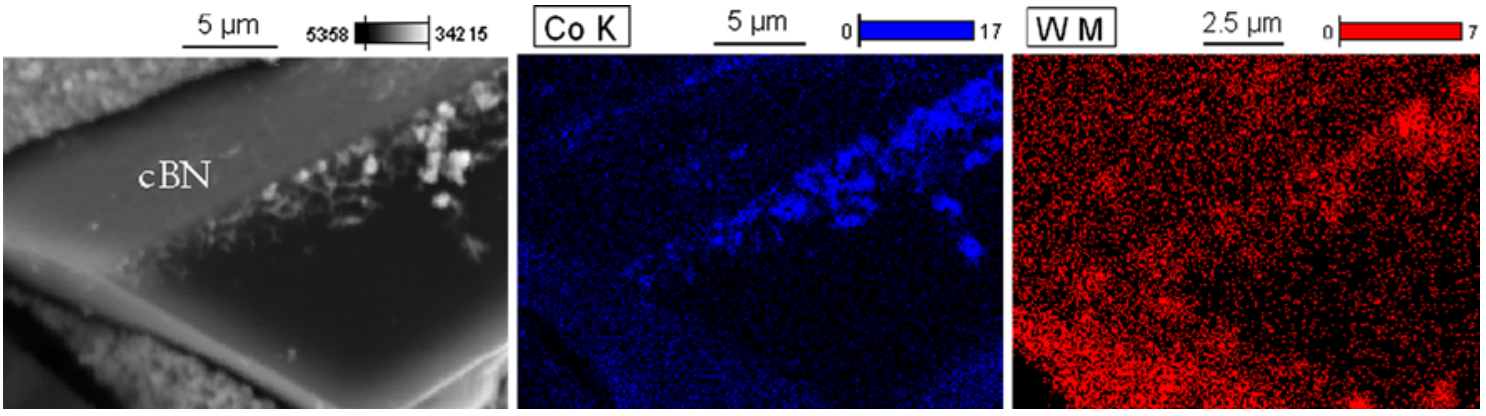

Fig. 10 Surface of a fracture of the $\mathrm{WC} 12 \mathrm{Co} / \mathrm{cBN}(37 / 44)$ composite sintered at $1,100{ }^{\circ} \mathrm{C}$ (EDS)
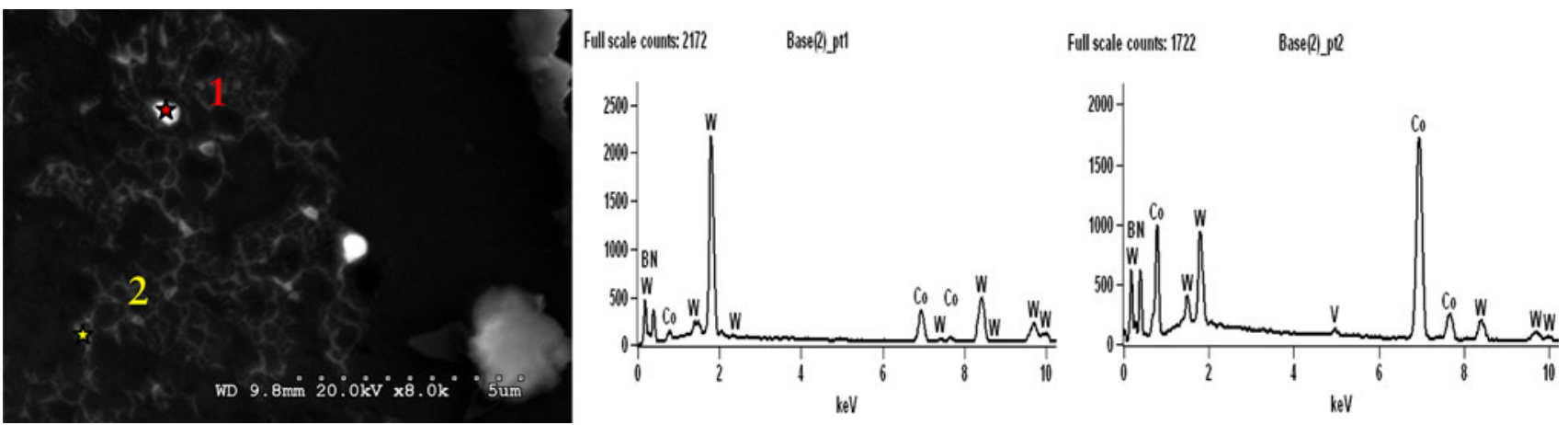

Fig. 11 Point EDX analysis of the $\mathrm{WC} 12 \mathrm{Co} / \mathrm{cBN}(37 / 44)$ composite sintered at $1,100{ }^{\circ} \mathrm{C}$

Phases of this kind have been observed to form in sinters obtained by sintering $\mathrm{WC}, \mathrm{Co}$, and $\mathrm{TiB}_{2}$ powders at temperature of $1,400{ }^{\circ} \mathrm{C}$ [14]. These phases can also occur as a result of reaction between $\mathrm{BN}$ and liquid cobalt and tungsten dissolved in it. In PPS sintering, the appearance of the liquid cobalt phase is associated with a rapid increase of the temperature by up to several thousand degrees Celsius during the flow of the current pulse through the material. This was demonstrated in our earlier study devoted to sintering of composites with a cemented carbide matrix containing dispersed diamond particles [11]. Figure 12 shows the variation of the hardness of the BNDCC composites with the sintering temperature for the various grades of $\mathrm{cBN}$ powder dispersed in cemented carbide matrix with 6 and $12 \mathrm{wt} . \%$ of $\mathrm{Co}$ added. Irrespective of the $\mathrm{cBN}$ powder grade or cobalt content, the hardness of the composites increased with increasing sintering temperature. The composites with 6 wt. $\%$ Co matrix sintered at temperature of $1,100{ }^{\circ} \mathrm{C}$ showed lower hardness than cemented carbide (2,110 HK1): the hardness of the WC6Co/cBN(1/3) composite was $2070 \mathrm{HK} 1$, and that of the WC6Co/cBN(37/44) composite was $1,990 \mathrm{HK} 1$. Increase of the sintering temperature to $1,200{ }^{\circ} \mathrm{C}$ resulted in an increase of the hardness to $2,330 \mathrm{HK} 1$ for the $\mathrm{WC} 6 \mathrm{Co} / \mathrm{cBN}(1 / 3)$ composite and to $2,160 \mathrm{HK} 1$ for the WC6Co/cBN(37/44) composite. For the composites with cemented carbide +12 wt. $\%$ Co matrix, those sintered at $1,100{ }^{\circ} \mathrm{C}$ had hardness of $1,880 \mathrm{HK} 1$, which increased to $1,950 \mathrm{HK} 1$ for the composite sintered at $1,200{ }^{\circ} \mathrm{C}$. The hardness of the $\mathrm{WC} 12 \mathrm{Co} / \mathrm{cBN}(37 / 44)$ composite sintered at $1,100{ }^{\circ} \mathrm{C}$ exceeded (by about $340 \mathrm{HK} 1$ ) that of the cemented carbide $+12 \mathrm{wt} . \%$ Co sintered at the same temperature. This increase in hardness may be due to the occurrence of the $\mathrm{WCoB}$ phase, whose hardness is on the order of $4,500 \mathrm{~kg} / \mathrm{mm}^{2}$, but diffraction examinations of these composites did not show the presence of the WCoB phase. It should, however, be realized that the diffraction peaks from the $\mathrm{WCoB}$ phase may be very weak because of the very high absorption coefficient of the WC phase.

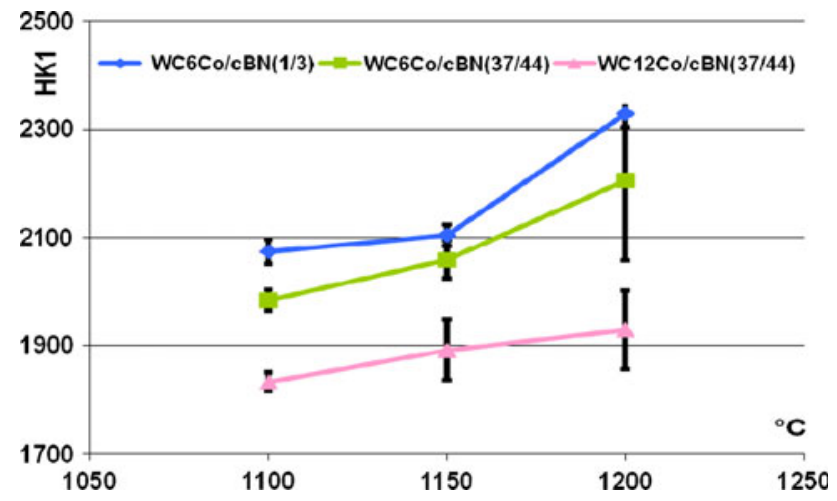

Fig. 12 Hardness versus sintering temperature of the BNDCC composites with $\mathrm{cBN}$ powders of various grades and the cemented carbide matrix with 6 and 12 wt.\% Co added 
Table 4 Hardness of BNDCC composites with WC 5 wt.\% Co matrix sintered by various methods

\begin{tabular}{lllll}
\hline Powder grade & Hardness & Sintering technique & $\%$ TD & Reference \\
\hline $2 / 4 ; 30$ vol. $\%$ & $2,150 \mathrm{HV} 5$ & HIP $\left(1,100{ }^{\circ} \mathrm{C} ; 200 \mathrm{MPa} ; 60 \mathrm{~min}\right)$ & 99.8 & {$[5]$} \\
- & $2,100 \mathrm{HV} 5$ & HIP $\left(1,100{ }^{\circ} \mathrm{C} ; 150 \mathrm{MPa} ; 60 \mathrm{~min}\right)$ & 100 & {$[5]$} \\
- & $1,860 \mathrm{HV} 10$ & SPS $\left(1,200{ }^{\circ} \mathrm{C} ; 50 \mathrm{MPa} ; 5 \mathrm{~min}\right)$ & 99.9 & 99.5 \\
$0.8 / 5 ; 25$ vol. $\%$ & $2,120 \mathrm{HV} 10$ & SPS $\left(1,300{ }^{\circ} \mathrm{C} ; 75 \mathrm{MPa} ; 7.5 \mathrm{~min}\right)$ & 99.5 & {$[7]$} \\
- & $2,100 \mathrm{HK} 1$ & PPS $\left(1,100{ }^{\circ} \mathrm{C} ; 100 \mathrm{MPa} ; 5 \mathrm{~min}\right)$ & 95.2 & This work \\
$1 / 3 ; 30$ vol. $\%$ & $2,330 \mathrm{HK} 1$ & PPS $\left(1,200{ }^{\circ} \mathrm{C} ; 100 \mathrm{MPa} ; 5 \mathrm{~min}\right)$ & This work \\
\hline
\end{tabular}

HK1 Knoop hardness, $1 \mathrm{~kg}$ load, HV5 Vickers hardness, $5 \mathrm{~kg}$ load, HV1O Vickers hardness, $10 \mathrm{~kg}$ load

Table 4 compares the hardness of BNDCC composites obtained by various investigators under nonequilibrium thermodynamic conditions of $\mathrm{cBN}$.

The hardness of composites with similar matrix chemical composition and similar $\mathrm{cBN}$ powder grade but sintered by the HIP and SPS methods is slightly lower than that of the composites sintered by PPS. The sintering time for the PPS and SPS methods is, however, more than ten times shorter than that required for the HIP method.

\section{Conclusions}

Composites containing the $\mathrm{cBN}$ phase dispersed in cemented carbide matrix were consolidated by the PPS method under nonequilibrium thermodynamic conditions of $\mathrm{cBN}$. The composites sintered at temperature of $1,200{ }^{\circ} \mathrm{C}$ under pressure of $100 \mathrm{MPa}$ for $5 \mathrm{~min}$ had density near the theoretical value. SEM observations of the microstructure and diffraction phase examinations did not show the presence of $\mathrm{hBN}$ phase. The specific heating conditions used to consolidate the material, using highcurrent pulses, hamper the transformation of $\mathrm{cBN}$ into $\mathrm{hBN}$ and ensure a strong bond between the $\mathrm{cBN}$ particles and cemented carbide matrix.

Acknowledgements This work was supported by project no. 0611/R/T02/2009/06 of the Polish Ministry of Science and Higher Education.
Open Access This article is distributed under the terms of the Creative Commons Attribution License which permits any use, distribution, and reproduction in any medium, provided the original author(s) and the source are credited.

\section{References}

1. Sumiya H, Uesaka S, Satoh S (2000) J Mater Sci 35:1181. doi: 10.1023/A: 1004780218732

2. Petrusha I (2000) Diam Relat Mater 9:1487

3. Shipilo VB, Ignatenko OV, Anichenko NG, Azarko II (2005) Inorg Mater 41:713

4. Angseryd J, Elfwing M, Olsson E, Andrén HO (2009) Int J Refract Met Hard Mater 27:249

5. Martínez V, Echeberria J (2007) J Am Ceram Soc 90:415

6. Upadhyaya GS (1998) Cemented carbides production, properties and testing. Noyes, Bracknell

7. Yaman B, Mandal H (2009) Mater Lett 63:1041

8. Shi XL, Shao GQ, Duan XL, Yuan RZh (2007) Key Eng Mater 336-338:1053

9. Kupczyk J, Michalski A, Siwak P, Rosinski M (2011) J ASTM Int 8(2)

10. Rosinski M, Michalski A, Szawlowski J (2011) Key Eng Mater 484:130

11. Michalski A, Rosiński M (2008) J Am Ceram Soc 91(11):3560

12. Ciupinski L, Siemiaszko D, Rosinski M, Michalski A, Kurzydlowski KJ (2009) Adv Mater Res 59:120

13. Shi XL, Shao GO, Duan XL, Xiong Z, Yang H (2006) Diam Relat Mater 15(10):1643

14. Saez A, Arenas F (2003) Int J Refract Met Hard Mater 21:13 